Project 1022497

\title{
Biotransformation involved in sustained reductive removal of uranium in contaminant aquifers
}

\author{
Lovley, Derek R. \\ University of Massachusetts
}

RESULTS TO DATE: This report summarizes progress made from August 2004 to July 2005. During this period research focused primarily on obtaining a better understanding of the factors controlling the reduction of $\mathrm{U}(\mathrm{VI})$ during in situ uranium bioremediation as well as investigating the potential for using electrodes as an alternative electron donor to promote in situ uranium reduction. Analysis of the 2003 experiment at the field study site in Rifle, $\mathrm{CO}$ was completed. The results demonstrated the substantial heterogeneity of the zone undergoing bioremediation, both in terms of geochemistry and microbiology. The lack of $\mathrm{U}(\mathrm{VI})$ reduction under sulfate-reducing conditions was clearly documented. The need for more detailed sampling both with time and with depth in the aquifer was demonstrated. For the first time a comparison between the composition of the microbial community in the sediments and the microbes in the corresponding groundwater was attempted. The findings from this study are important not only in further demonstrating the potential for in situ uranium bioremediation, but also for indicating how methods and sampling approaches should be improved in the future. A manuscript summarizing these findings has been accepted for publication in Applied and Environmental Microbiology. In summer of 2004 a new field experiment was conducted at the Rifle site. A novel feature of this study was much more intensive sampling in order to better define the progression of microbial processes during in situ uranium bioremediation. The results demonstrated that stimulation of in situ uranium bioremediation with added acetate was a repeatable phenomenon and that $\mathrm{U}(\mathrm{VI})$ reduction was clearly linked to the presence and activity of microorganisms in the family Geobacteraceae. A manuscript summarizing these results is in preparation. A surprising result of the field studies at the Rifle site was that although Geobacter species actively reduced $\mathrm{U}(\mathrm{VI})$ in the groundwater, removing it from solution, a high percentage of the uranium in sediments was recovered as $\mathrm{U}(\mathrm{VI})$. In order to evaluate this further, studies were conducted in which sediments from the Rifle site were incubated under strict anaerobic conditions. This permitted accurate monitoring of the uranium speciation in the sediments as well as in the groundwater over time. When acetate was added to simulate the in situ uranium bioremediation strategy, $\mathrm{U}(\mathrm{VI})$ in the groundwater was reduced with a corresponding increase in $U(I V)$ in the sediments. However, the $U(V I)$ in the sediments was not reduced, even after long-term incubations. The resistance of $\mathrm{U}(\mathrm{VI})$ adsorbed to sediments to microbial reduction was not previously suspected and has important implications for in situ uranium bioremediation. These results indicate that in order to concentrate all of the uranium contamination into discrete zones a method for first releasing then reductively precipitating the uranium is required. $A$ manuscript summarizing these findings was published in Applied and Environmental Microbiology. The field studies at the Rifle site have demonstrated that acetate is a very effective electron donor for promoting microbial $\mathrm{U}(\mathrm{VI})$ reduction in the subsurface. The only limitation to this technique is that although further migration of uranium is prevented, the uranium still remains in ground. In an attempt to avoid this, studies were initiated with electrodes serving as an electron donor, as outlined in last year?s report. Continued studies clearly demonstrated that electrodes could serve as an electron donor to support $\mathrm{U}(\mathrm{VI})$ reduction by Geobacter species. Studies conducted in flow-through columns designed to mimic conditions at the Rifle site, effectively removed $\mathrm{U}(\mathrm{VI})$ from the groundwater. A larger scale system was successfully tested in a 55 gallon drum in anticipation of testing this technique at the Rifle field site this summer. An advantage of the electrode method is that the $\mathrm{U}(\mathrm{IV})$ that is produced from $\mathrm{U}(\mathrm{VI})$ reduction precipitates on the surface of the electrode. Thus, when the electrode is removed from the subsurface the uranium is also removed. In this way, not only is the further spread of uranium in the groundwater prevented, but the uranium can also be removed from the subsurface. A manuscript summarizing these results received favorable reviews from Environmental Science and Technology and the revised manuscript has been returned to the editor. Another surprising result from the field studies at Rifle has been that once Fe(III) is depleted from the sediments closest to the injection gallery and sulfate reduction becomes an important process, there is little, if any, $\mathrm{U}(\mathrm{VI})$ reduction under sulfate-reducing conditions. It was hypothesized that this was because acetate-oxidizing sulfate-reducing microorganisms 
are not known to be effective $\mathrm{U}(\mathrm{VI})$ reducers. Therefore, studies were conducted in which Rifle sediments and groundwater were incubated under anaerobic conditions to simulate those at the Rifle site and lactate was added as the electron donor. Lactate was used because lactate is a preferred substrate of Desulfovibrio species and our previous studies have demonstrated that Desulfovibrio are effective U(VI)reducing microorganisms. However, in repeated attempts, the addition of lactate did not stimulate the growth of Desulfovibrio or $\mathrm{U}(\mathrm{VI})$ reduction under sulfate-reducing conditions. These results have important implications for the potential to promote $\mathrm{U}(\mathrm{VI})$ reduction under sulfate-reducing conditions. They also suggest that pure culture studies with Desulfovibrio are unlikely to provide useful information on $\mathrm{U}(\mathrm{VI})$ reduction during in situ uranium bioremediation. A first draft of a manuscript summarizing these studies has been completed.

DELIVERABLES: Ortiz-Bernad, I., R. T. Anderson, H. A. Vrionis, and D. R. Lovley. 2004. Resistance of solid-phase $\mathrm{U}(\mathrm{VI})$ to microbial reduction during in situ bioremediation of uranium-contaminated groundwater. Appl. Environ. Microbiol. 70:7558-7560.

Lovley, D. R., D. E. Holmes, and K. P. Nevin. 2004. Dissimilatory Fe(III) and Mn(IV) reduction. Adv. Microb. Physiol. 49:219-286.

Lovley, D. R. 2005. In situ biology meets in situ phenomenology. Environ. Microbiol. 7:478-479.

Vrionis, H. A., R. T. Anderson, I. Ortiz-Bernad, K. R. O'Neil, C. T. Resch, A. D. Peacock, R. Dayvault, D. C. White, P. E. Long, and D. R. Lovley. 2005. Microbiological and geochemical heterogeneity in an in situ uranium bioremediation field site. Appl. Environ. Microbiol. 71:(in press).

Gregory, K. B., and D. R. Lovley. 2005. Remediation and recovery of uranium from contaminated subsurface environments with electrodes. Environ. Sci. Technol.:(submitted).

Ortiz-Bernad, I., H. A. Vrionis, R. T. Anderson, and D. R. Lovley. 2005. Persistence of uranium(VI) under sulfate-reducing conditions in uranium-contaminated sediments. Appl. Environ. Microbiol.:(to be submitted). 